\title{
The Introduction of Non-profit Organization Marketing Motives, Routines and Strategies for "New Rural Co-operative Medical System": Resource Dependence Perspective

\author{
Wei-Zhen Yu
}

\author{
School of Management, Zhejiang Shuren University, Zhejiang Center for Modern Service \\ Research, Hangzhou, Zhejiang, 310015, China
}

Keywords: NCMS, NPO, Marketing strategies, Resource dependence.

\begin{abstract}
New Rural Cooperative Medical System (NCMS) is one of important parts of the rural social security system, which is also an important measure for the governments to solve the problems about agriculture, rural areas and peasantry and to build socialist harmonious society. Most studies mainly focus on the macro system design and the fairness of the micro operation mechanism and implementation, which almost rely on the government single supply mode. However, the gap between "government ability" and "farmers needs" increases the new rural cooperative medical resource constraints. This has become the biggest obstacle to the sustainable development for NCMS. Focusing on the organizational characteristics and difficulties of NCMS, this paper attempts to improve the effects of non-profit organization (NPO) functions by adopting marketing strategies. So it can interact with the external environment development and access to resources actively. The paper puts forward some strategies for NCMS' cooperative marketing, and also attempts to seek suitable cooperation partners and marketing means to match different development periods. By doing this, a stable resources access network can be established so as to provide more comprehensive protection for the NCMS' sustainable development.
\end{abstract}

\section{Introduction}

New Rural Cooperative Medical System (NCMS), an important reform of China's rural medical system, that focuses mainly on the resolving of the problem of "poverty due to illness; poverty reinstatement due to illness", has now developed to the period of "delivering national welfares"(Li Bing, 2012). Medicare services have become the necessities in farmers' daily life (Ye Minghua, 2011). In June, 2013, Premier Li Keqiang demanded explicitly for the first time that rural medical services should be provided as a kind of public goods. At present, NCMS is in the stage of moving from middle-proliferation pattern to demand-derivation pattern, that is, the change from "supply-oriented" to "demand-oriented" and the elasticity of demand is big (Luan Xiaoping, 2009; Ren Gang, 2012). Moreover, as China's rural aging population problem is worsening; the pressure of the rural medical insurance payment will increase gradually (Sun Jian, 2009). The contradiction between the farmers' growing demand for medical services and the additional finance investment from the government are getting more and more sharp, which is a serious impediment to the healthy and sustainable development of NCMS. According to the present studies, the implementation of NCMS doesn't seem to work well (Cheng Lingguo, 2002). On one hand, the effect of NCMS' reducing spending on serious illness and poverty due to illness is limited (Yip \& Hsiao, 2009; You \& Kobayshi, 2009; Sun et al, 2010). On the other hand, NCMS didn't reduce the medical burden of its participants (Lei \& Lin, Wagstaff et al, 2009). According to the survey, farmers' satisfaction toward NCMS is more about the recovery of the system, that is, the satisfaction of the "quantity" of NCMS rather than its "quality" (Yu Weizhen, 2010). Xiao Shishun (2008), by carrying out an 
empirical analysis through using Expected Utility Theory and Demand Theory, points out that NCMS is far from the expectation of farmers' needs. The prominent problem include, serious shortage of funds, low level of security and poor level of medical service, etc. (Tang Jianxin, 2010). Economic factors such as medical expense are still the major determinants that will influence farmers' decision of whether or not seeing a doctor (Wang Yiqiu, 2009).

The existing NCMS policies show government's determination to undertake rural medical service. However, at the same time, the state interference affects the market fundamental role in the allocation of resources because the government-leading model ignores the positive role of social participation in the management of NCMS to improve public service. The researches about NCMS are mainly focus on the designing of NCMS system by government and the fairness of its implementation (Li Liqing, Chengyi, 2012). Seeking innovative ideas that will guarantee a diversified and dynamic development has become the important strategic choice of rural social security in many developing countries. Zhang Jingjing's (2007) research shows that, from the theories of international medicare economy and institutional reform trend, the development of NCMS neither follow market-oriented model nor stick to state-oriented model, but pays more and more attention to the integration and complementary of the two models. The government should play the leading role, and the market as a supplement at the same time. Their relationship is not either this or that (Meng Lingyun, 2009).

The constant improvement and sustainable development of NCMS are particularly important to the reduction of farmers' medical burden, alleviation the problem of "proper health care is difficult to get" and "proper health care is expensive" and to the construction of new countryside and harmonious society. The essence of the dilemma of the sustainable development of NCMS is its "resource constraints" and the present researches about resource acquisition and mode selection of NCMS are more confined to "passive blood transfusion" and from the prospect of the dependence of external resources. Therefore, the research on the integration of government with market in which government plays the leading-role and market as a supplement as well as how to use NCMS in "hematopoiesis" by playing their initiative to obtain the social resources in market remains to be expanded and deepened.

\section{Literature Review and Theoretical Deduction}

As NCMS is a typical non-profit organization (NPO) (Jiang Yuansheng, Xiao Shishun, 2008), it will inevitably lead to "government failure" or "market failure" (Stigitz, J.E., 1998; $\mathrm{Hu}$ Shanlian, 2002). In order to make up for this deficiency or defect, we need to make full use of the function of NPO (Weisbrod, 1974; Hansmann, 1980). MCNS plays a supplementary role when there is a serious shortage of government investment, which is irreplaceable in the building of new countryside and harmonious society (Wang Ruiping, 2007). As NCMS has the typical characteristic of "customer resource dependence" and "high degree of resource dependence", the implementation of marketing-oriented strategy will reduce the NPO's dependence on the external environment and increase the external environment's dependence on NPO at the same time. Marketing-orientation is its possible strategic choice under the situation of resource dependence, as shown in Figure 1 ( $\mathrm{Hu}$ Yangcheng, 2008).

NCMS supplies public goods (He Dun, 2007; Luan Xiaoping, 2009) and with the development of economy and society, it is difficult to meet the diverse and complex needs of farmers' to NCMS, which depends totally on the government's supply of rural public goods (He Anhua, 2013). Government's leading role in the supply of rural public goods doesn't mean the supply of it can only adopt one single mode. The best constitution of rural public goods is not government's spending or personal consumption, but the dynamic integration of 
government, market and NPO. By this integration, we can set up various levels and degrees of competition mechanism according to the different demand levels of public goods to enhance the alternative function of public goods and private goods. Only by this can we set up the supply mode that is multi-agent, multi-channel and multi-method according to farmers' consumption choices. It is set up by taking into consideration of the main body of supply, the resources of funding and the method of supply. So we can maximize the effectiveness of rural public goods consumption, improve the micro efficiency of rural public goods supply (Buchanan, 1968; Zhangxi, 2006). Former Premier Wen Jiabao put forward clearly in 2011 Government Work Report that "NPO should play a positive supplementary role in the social security". Yuanqian (2013) analyzed the reason and feasibility of the independent supply rural public goods. According to the international medical security experience, whether it is developed or developing countries, no matter what kind of security model they adopt, NPO plays a significant role (Gu Xin, 2006).

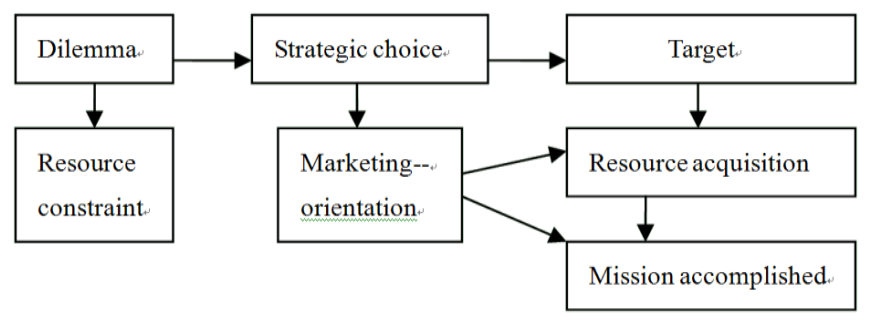

Fig. 1 difficult situation NCMS facing and strategy choice

According to the researches from the relationship of the marketing strategy and the performance of non-profit medicare organization, the result seems to be consistent both at home and abroad. And the empirical researches basically prove that the two have positive correlation relationship (Kara, Pedanyi, Gainer, 2004; Hu Yangcheng, 2009; Mohammed Abdulai Mahmoud and Baba Yusif, 2012 etc.). NPO can make more efficient access to resources by improving its level of marketing orientation, which can be carried out by enhancing donor's enthusiasm and satisfaction through improved service as well as its overall performance (Smith et al, 1994; Gonzalez et al, 2002). According to Sara Dolnicar and Katie Lazarevski's (2009) empirical research on many developed and developing countries, the performance of medicare NPO can be improved significantly by introducing marketing strategy, showing consistency with no significant difference among countries.

In view of this, the situation in which rural public goods is led by government and supplied by multi-agent has gradually formed. The consensus that NPO is the preferred subject has been reached ( Dong Mingtao, 2010; He Anhua, 2013 etc.). however, NCMS, the typical rural public goods, is currently rely on government-supply mode, that is, totally depends on "passive blood transfusion" from outside. How to achieve the mode in which multi-agent, multi-channel and multi-method means of supply co-exist to establish a stable resource acquisition network is the key factor to break the new resource dilemma in the development of NCMS. The related research such as how to make use of its characteristic as NPO, play its own initiative and seek external resource is still relatively rare. Although almost all the domestic and foreign scholars agree that the performance of security type of medicare NPO can be improved by introducing marketing strategy, their researches focus on the relationship between organizations and their performance as well as its practicability. The previous researches lack the systematic research as how the NPO with positive performance introduce and implement marketing strategy, what is the routine of realization (Hou Jundong, 2009). In this paper, the author discuss how to provide more comprehensive guarantee for NCMS' 
sustainable development by introducing marketing strategy to start the interaction with other organizations, which will reduce its dependence on other organizations and increase the other organizations' reliance on NCMS. By introducing marketing strategy, NCMS will create and obtain more social resources such as funds, personnel, management and service in the market to promote its supply level and improve the dilemma of resource constrains, that is, to change from "passive blood transfusion" to "positive blood producing".

\section{Analysis on the Motivation of NCMS' Introduction Marketing Strategy}

Sustainable marketing will maximize the needs of the "buyer" and "seller". NCMS, as a type of NPO, has different goals and needs compared to other organizations. On one hand, the motivation of participating marketing is different. On the other hand, the influence of cooperation on external organizations or NCMS may also be different even when their motivations are same. Therefore, it is necessary to inspect the motivation of this inter-organization cooperative marketing from NCMS and external organizations respectively. The NCMS buyer's market mainly involves the participation of government, farmers (users), enterprises, the public, foundations, etc. this paper focuses on two major buyer's markets, that is, enterprises and public, by taking into the consideration that based on the existing NCMS policy, the government and farmer participants are policy-oriented.

\section{From the aspect of NCMS}

The public goods provided by NCMS, a typical NPO, will inevitably lead to "government failure" and "market failure" in the actual operation process, which determines the necessity of the existence of this NPO. Medicare in the world is generally facing the plight of resource constraints, which is particularly prominent in China's NCMS under the background of institutional transformation. Obviously the government cannot solve all these problems. When NCMS can not obtain the necessary resources through markets or by internationalization, it must work with other organization to gather, share or exchange these resources (Hu Yangcheng, Caining, 2008). The implementation of marketing strategy is an important way to NCMS to obtain resources, which diversifies the potential benefits and reduces its dependence on government funding (Sagawa, 2002). To improve the supply of "product", as shown in Figure 2, the optimal supply of public goods in Q1 to individual; when the public goods has the effect of positive externalities, the optimal supply is Q2.

The introduction of new medical reform program creates a space for the market operation of NCMS. The new medical reform program improves the efficiency of medical resources allocation and its level of security. The allowing of flowing in of social capital creates the quasi-market competition mechanism for NCMS organization, which provides a vast space for the market-oriented operation to release its energy and realize the organization mission.

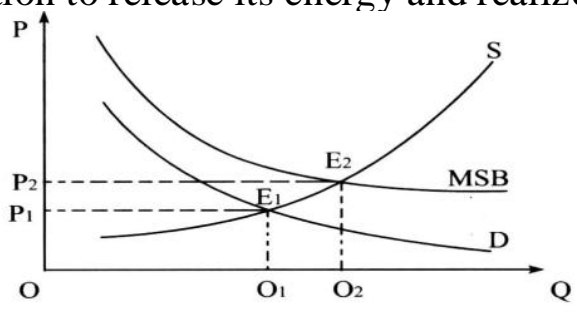

Fig. 2 supply and demand of public goods

By building partner relationship with celebrities and build a good reputation in society and promote social cognition (Bendell, 2000). At the same time, it can create opportunity for 
NCMS to win those customer groups that belong to enterprise originally. NCMS can also gain benefit from the knowledge transfer between departments especially form the learning of efficient management and operating mode in enterprise sectors (Rondinelli, London, 2004). The knowledge such as new skills and business management that NCMS learn from its corporate partners is helpful for the promotion of its overall operation efficiency and its performance.

\section{From the perspective of external organizations (public and enterprises)}

The problem is discussed from the following two aspects. One is the donation motivation form social public moral. Social public donation is a kind of participative behavior with the characteristic of moral oversimplification which helps the poor and care for the needy. The participation motives can be divided into three kinds, that is, ideological sustenance, good wishes and moral salvation. The other is the donation motivation from enterprise economy. To gain benefit is the fundamental motive of an enterprise's donation. At the same time, more and more enterprises are willing to take on more social responsibility the enterprise can improve it corporate citizenship to enhance its public image and public awareness. The staff's organizational identity and work enthusiasm can be stimulated by participating in community development and volunteer activities. At the same time, staff's skill training and employee's retention can be improved; therefore employee's turnover rate and the cost of human resources can be reduced, which will improve the overall productivity. Enterprises can increase their market share and reduce the entry and operation risk by effectively selecting target customer and moral practice (Austin, 2000). There are differences in the structure, culture and core mission between enterprises and nonprofits. The multi-level communication and exchange between the two will help to broaden the vision of enterprise's employees and create unique learning opportunities. All of these benefits cannot be achieved by the communication and exchange inside the departments (London, Rondinelli, 2004). In summary, the motivations of NCMS' introduction marketing strategy are shown in Table 1.

Tab. 1 the motivation of NCMS' introduction of marketing strategy

\begin{tabular}{|c|c|}
\hline motivations of NCMS organization & $\begin{array}{l}\text { motivation of external organization } \\
\text { (the public and enterprises) }\end{array}$ \\
\hline $\begin{array}{l}\text { characteristics of NPO } \\
\text { External access to resources } \\
\text { new medical reform providing operation space } \\
\text { for } \\
\text { marketization } \\
\text { the study and transferring of knowledge to } \\
\text { create new synergies } \\
\text { motivating members to promote organization } \\
\text { performance } \\
\text { to raise the supply level of medical public goods }\end{array}$ & $\begin{array}{l}\text { gain legitimacy } \\
\text { donation motives } \\
\text { social responsibility } \\
\text { to establish and expand public } \\
\text { relations } \\
\text { the study and transferring of } \\
\text { knowledge } \\
\text { to create new synergies } \\
\text { to motive employees and promote } \\
\text { performance }\end{array}$ \\
\hline
\end{tabular}

Data source: the related literature

\section{Marketing strategy and routine selection of NCMS as NPO}

\section{Mission priority}

Robert E. McDonald (2007) thinks that the main feature of an outstanding NPO is that, it has a mission that has been clearly defined and has been approved and cherished by all 
members. Only with a clearly defined mission can a goal be clearly defined. It is the mission that decides the success or failure of a NPO. Gelatt also thinks that the reason of the existence of the organization is the completion of its goal. Therefore, one of the biggest differences between NPO and profit-making organization is that NPO takes mission first. And it is not by salary, welfare but by its commission that NPO attracts its employees and volunteers (Deng Guosheng, 2001). NPO need to convert the mission into specific strategy after it has clearly defined mission. The strategy of NPO is derived from its mission. However, strategy is more concrete than mission and it has the characteristics of stages. A strategy is guidance for action that must be taken for the future ideal (Situ Xianda, 1999). The NCMS mainly solve the problem of "proper health care is difficult to get" and "proper health care is expensive" as well as "poverty due to illness and poverty reinstatement due to illness". A mission or an objective like this is defined with a macro statement and it need to be refined to an accurate description. In order to seek suited "customer", it need to be refined to an accurate description, location and spreading.

\section{The strategy and process of NCMS' introduction marketing}

The essence of NCMS' introduction marketing is the attracting and allocating resources as well as persuading. By cooperative marketing with other organizations, NCMS realizes the complementary advantage of resources enhances the development of market and strengthens its ability to develop and penetrate into a market as well as its competitiveness. It reaches a long-term or short-term cooperative alliance to develop and market jointly. NCMS initiates activities by using various marketing means actively. It analyzes marketing strategy, makes marketing plan, and expands resources to look for partners that share common interests. It achieves a win-win effect by establishing a win-win partnership, gathering organization's advantage to improve its competitiveness and "autonomy", which will make NCMS reach the professional and technical level, provide better medical service and achieve better social benefits. In this process, it is necessary to implement marketing strategies and follow some certain steps and strategies, which is shown in Figure 3.

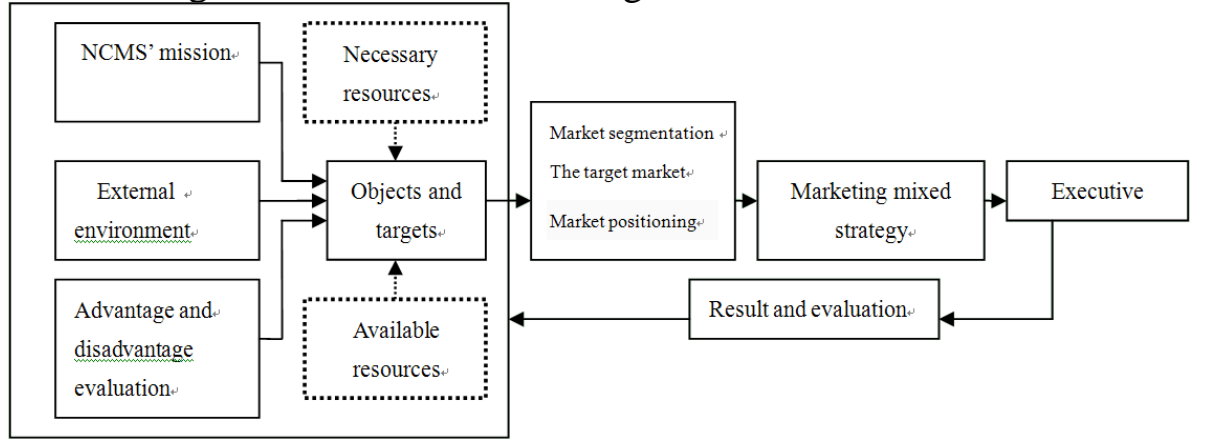

Fig. 3 the theoretical operation mode and process of strategic NCMS cooperative marketing planning

\section{The cooperative marketing mode based on the realization of NCMS' goal and the path selection}

NCMS' cooperative marketing with the public. NCMS' marketing communication to the public is different from the enterprises' marketing communication because it development is for the purpose of spreading its principles. Its goals include, confirming the public demand, building brand image, attracting volunteers, raising funds, spreading organization's principle and fulfilling its mission. The self-marketing of NCMS and the emphasizing of its principle and service object are carried out for the purpose of winning the public's trust, which lays the 
foundation for the organization of its work. To develop volunteers and raise funds is to provide the organization with necessary staff and cost; to spread NCMS principles and implement "concept marketing" is to make more people accept th concept of the organization and give active support in thought and action. Wang Shifeng(2001) divides the public into four groups according to their contributions to NPO (Figure 4). It is the ultimate purpose of NCMS to "marketing" the public as contributes.

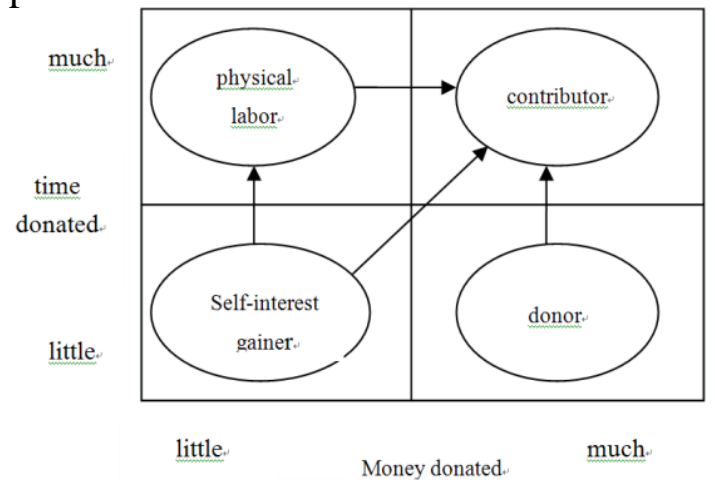

Fig. 4 four groups of the public

NCMS' cooperative marketing with enterprises. From the end of last century, western scholars have classified the affiliate marketing modes of enterprise and NPO from the perspective of market. (Varadarajan,menon, 1998; Andreasen, 1996; Drumwright, 1996; Cornwell, Maignan, 1998) After entering into the 21st century, as the NPO and enterprise cooperation marketing constantly extend and expand in content and form, many scholars start to work from the perspective of strategic management to exam the cooperative relation of inter-department and pay attention to the dynamic evolution process of NPO and enterprise cooperation.(Bendell, 2000; Austin, 2000; Wymer, Samu, 2003; London, Rondinelli, 2004; Galaskiewicz, 2005)

(1) The choice of cooperative method between NCMS and enterprises

According to respective motive and the expectation of building cooperative relation, Andreasen puts forward three ways of cooperation between NPO and enterprises, that is, the activities of public promotion associated with business, the theme marketing, and the marketing by issuing licenses. Wymer and Samu have divided the NPO and enterprise's cooperative way into seven types: corporate philanthropy, corporate fund, the license agreement, sponsorship, some promotions based on trading, shared theme and joint operation. At the same time, they have identified the focus on two key dimension analyses of NCMS organization and enterprise (horizontal dimension in Figure5) and the source of right control (longitudinal dimension in Figure5). Different types of cooperation show differences in motivation and control (see Figure 5).

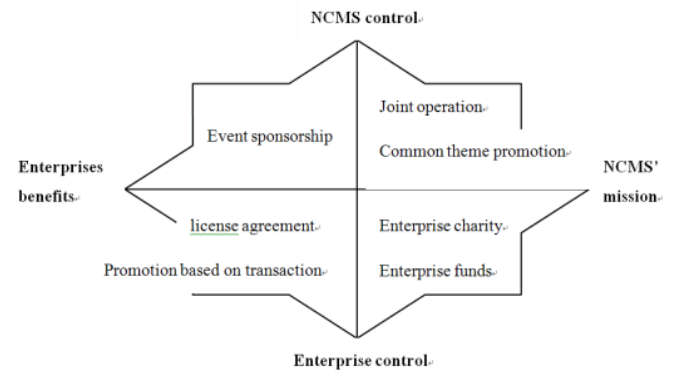

Fig. 5 two-dimensional classification of NCMS' cooperative marketing 
The key for the successful development of NCMS' cooperative marketing is to choose its appropriate cooperate way and good partner (Andreasen, 1996; Berger, 2004). According to Figure 5, when the cooperative benefits and risk control are taken into consideration by the manager of NCMS, they will find out the enterprise cooperative target and their expectations of profit level based on different relation types and choose the reasonable cooperative type combines with their goals (Wymer and Samu, 2003). And they will adopt different managemental modes according to different motivation and risk. Moreover, the manager of NCMS also should seek the right cooperator. Drumwright and Berger have defined different types of NPOs--the matching model of enterprise relation, described the mission match, resources match, management match, members match, target market match, product/enterprise match, culture match, cycle match, evaluation match. The nine above dimensions are based on Austin and Sagawa's case study, apparently, management match is the most critical.

In order to establish a stable, continuous cooperative relation with the external organization, the NCMS also should consider the dynamic evolution process when the NCMS is on the way to sustainable development and make the partner selection decision.

(2) The dynamic evolution process of NCMS cooperation with enterprise

In terms of the experience of world health care NPO as well as the empirical research of Austin(Austin,2000), NPO and enterprise's cooperation, generally speaking, will experience charity, trade, integration development stages, the evolution process is called collaboration continuum (CC). Austin further points out that the partnership has its importance at each stage, and they share an equal status; while it is not a standard mode, it needn't experience each stage of development in accordance with such a time sequence. This interact process of cooperation is flexible, because the decision maker of NCMS can set the cooperative mode as the basis of carrying out the actual interaction among partners according to the development of organization and its periodic demand.

It can be found from the above analysis that Wymer and Samu are mainly based on the point of marketing and focus on the cooperative transaction attribute, while CC mode is concentrated on the quality attribute of cooperative relation. There is a certain degree of complementarities between the two modes. Selective way of cooperation exists in different stages of development (see Table 2)

Tab. 2 the choice of the method of cooperation of NCMS and enterprise in specific stage

\begin{tabular}{|c|c|c|}
\hline $\begin{array}{c}\text { charity stage } \\
\text { enterprise charity } \\
\text { enterprise funds }\end{array}$ & $\begin{array}{l}\text { transaction stage } \\
\text { promotion of common theme } \\
\text { event sponsorship promotion } \\
\text { based on promotion }\end{array}$ & $\begin{array}{c}\text { consolidation stage } \\
\text { joint operation } \\
\text { license agreement }\end{array}$ \\
\hline
\end{tabular}

(3) The driving forces and promoting factors of NCMS' cooperative marketing with enterprises

It is an important path to acquire external resources for NCMS to carry out sustained successful cooperative marketing with enterprises. What factors will affect the success of cooperation is the problem that NCMS policymakers will take into consideration. Austin(2000) divided the factors that will influence the success of cooperation into three dimensions, that is, the driving forces for cooperation, the contribution factors and the building of value in the process of interaction. The researches of driving forces include the consistency of the strategy, missions and values, interpersonal emotional ties and relationships, the production of value, the shared vision and continuous learning, which the author of the paper calls it as the "thrust" of cooperative marketing. Promoting factors, which is called as 
"tensile force" by the author here, include focus, communication, system structure, expectation and obligation of each other. The building of value which is called by the author as "viscous force" includes the confirmation of cooperation value and the expected value being produced continuously for each other, the balance of exchanged value between the two sides, the innovation value. In different period, these elements exhibit different characteristics (see Table 3).

Tab. 3 factors affecting NCMS cooperative marketing with enterprises and analyses in different development periods

\begin{tabular}{|c|c|c|c|c|}
\hline dimensions & elements of connotation & $\begin{array}{l}\text { charity } \\
\text { period }\end{array}$ & $\begin{array}{l}\text { transaction } \\
\text { period }\end{array}$ & $\begin{array}{c}\text { consolidation } \\
\text { period }\end{array}$ \\
\hline \multirow{4}{*}{$\begin{array}{l}\text { driving force } \\
\text { of } \\
\text { co-marketing } \\
\text { (the thrust) }\end{array}$} & $\begin{array}{l}\text { accordance of NMS's mission } \\
\text { and enterprise's value }\end{array}$ & $\mathbf{\square}$ & - & $\square$ \\
\hline & $\begin{array}{c}\text { network relationship between the } \\
\text { members of organization }\end{array}$ & & $\square$ & $\square$ \\
\hline & $\begin{array}{c}\text { shared vision and value toward } \\
\text { cooperation }\end{array}$ & घ & 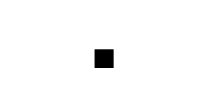 & $\square$ \\
\hline & $\begin{array}{c}\text { continuous learning in } \\
\text { cooperation }\end{array}$ & & $\square$ & ш \\
\hline \multirow{5}{*}{$\begin{array}{l}\text { promoting } \\
\text { factors of } \\
\text { co-marketing } \\
\text { (tensile } \\
\text { force) }\end{array}$} & $\begin{array}{c}\text { investment load of the leaders of } \\
\text { organization }\end{array}$ & $\square$ & ш & $\square$ \\
\hline & the openness and trust in & & ( & 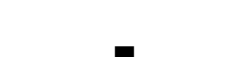 \\
\hline & communication in interactive & & $\square$ & D \\
\hline & $\begin{array}{c}\text { whether calls up for the setting of } \\
\text { cooperative team for resource } \\
\text { forming }\end{array}$ & & $\square$ & घ \\
\hline & $\begin{array}{l}\text { allocation of expected rights and } \\
\text { obligations }\end{array}$ & & $\square$ & - \\
\hline \multirow{4}{*}{$\begin{array}{l}\text { value } \\
\text { building of } \\
\text { co-marketing } \\
\text { (viscous } \\
\text { force) }\end{array}$} & $\begin{array}{l}\text { confirmation of the value of } \\
\text { cooperation and value }\end{array}$ & घ & घ & घ \\
\hline & $\begin{array}{l}\text { expected value being created } \\
\text { continually for each other }\end{array}$ & & च & - \\
\hline & $\begin{array}{l}\text { balance of exchanged value for } \\
\text { sustainable cooperation }\end{array}$ & & $\square$ & $\square$ \\
\hline & $\begin{array}{l}\text { innovation of sustainable } \\
\text { cooperation value }\end{array}$ & & $\square$ & $\square$ \\
\hline
\end{tabular}

Data source: modification of Austin's (2000) research. a connotation of the existing elements, $\square$ connotation of the forming elements

\section{Conclusion and Prospect}

Even though the NCMS has been developing continually and steadily, it has an obvious characteristic of "congenital deficit and acquired disorders" when facing the plight of resource restraining in its sustainable development. There is a big gap between it and other similar Rural Medical Security Organizations in foreign countries in achieving and operating resources, coordinating relationship and playing the role. Even though the difficulties of NCMS is associated with the background of macro social system during the transition period, how to improve its own governance capacity is a topic which can not be avoid in the 
process of the development of NCMS. The paper starts with the analysis of the structural characteristic of NCMS and the realization of its role and the reduction of the dependence on external environment: from the perspective of resources dependence of NPOs, this paper conducted a theoretical analysis on marketing orientation of our country's NCMS and made a exploration on how to realize it. The analysis and exploration makes the initiative of NCMS strengthened and NCMS interact with the outside world actively. Therefore, it has changed from depending on resources passively to getting resources initiatively. The paper not only expands the existing theory of marketing orientation but also offers some enlightenment for NCMS to achieve more resources and increase its own initiative and power of management.

(1)The NCMS are facing very complex external ecological environment, especially NPOs which provide social medical service often maintain intricate relationships with a variety of actors (such as donors, beneficiaries, volunteers, public media, partners, community health care, government departments, etc). Managers should establish a government-led "multi-management" thinking. They can not rely entirely on the government for the survival and development of NCMS. Instead, they need to identify and assess the groups of core participants who have a close connection with NCMS and take suitable management and marketing strategies for different needs and preferences. By doing these, they can establish good and long-term partnership and remain the survival and development of the NCMS in complicated environment.

(2) Managers should establish a concept that they should firstly accomplish the mission of the NCMS and take the mission as the direction of future development. Besides, they should overcome the bias that making out the development strategies of the NCMS is just the responsibilities of managers and consider the development of the stakeholders of the NCMS by making decisions in bottom-up process.

(3)Only when the NCMS organizations achieve sustainable, stable and adequate supply of resources can they provide high quality health care services to meet the needs of farmers. However, resource dilemma is just the weakness of the sustainable development of the NCMS. On the one hand, governments should create larger institutional environment for the NCMS by revising and improving relevant laws and regulations. On the other hand, the NCMS organizations also need to explore ways to obtain resources actively under the existing system. Such as, under the premise that their own position and purpose are not violated, governments should establish partnerships with the public and enterprises and work with them to provide social and medical services. They also should attract volunteers to take part in the activities hold by the NCMS by the appeal of organizations and leaders and get funds which are necessary to maintain the normal operation of the organization through providing professional services under the premise of maintaining the non-profit characteristic. In a word, the NCMS needs to take advantage of its creativity to establish a solid network to accessing resource.

Although some meaningful conclusions is put forward the paper, some restrictions still exist: (1)As NCMS' introduction marketing strategy is an operation that theory comes before practice, managers not only need courage to reform for realizing the target of the NCMS but also need to choose a suitable region to launch pilot project, improve and popularize gradually. Therefore, the study of this paper needs to be examined and improved by practice and makes the research worth to be popularized. (2)The NCMS is an important initiative to implement the Party Central Committee's policy of building a new socialist countryside. It is a policy to reduce farmers' burdens and will benefit the agriculture. The NCMS itself is a very complicated problem. The paper only carries analysis on the structure characteristic of NCMS and its dilemma, then proposes appropriate measures. I hope that it can draw the relevant institutions and scholars' attention in the future to build the theoretical framework systematically for NCMS' sustainable development. Let's work together to promote the 
NCMS' sustainable development to enhance the level of farmers' medical security.

\section{Acknowledgement}

2013 Zhejiang Province Civil Administration Policy Theory and Research Project Planning, Project Number: ZMZC2013079

\section{References}

[1] Brown,P.H.,A.De Brauw and Y.Du, 2009, "Understanding Variation in the Design of China's New Cooperative Medical System”, China Quarterly, 198: 304-329.

[2] Brown,P.H.and C.Theoharides, 2009, "Health-Seeking Behavior and Hospital Choice in China's New Cooperative Medical System”, Health Economics, 18, S2: S47-S64.

[3] Sara Dolnicar and Katie Lazarevski, Marketing in non-profit organizations: an international perspective[J], International Marketing Review ,Vol. 26 No. 3, 2009 ,pp. 275-291.

[4] Zhang guangke. The Research Situation and Prospect of the New Rural Cooperative Medical System[J],Agriculture Economic Problem, 2010(1):67-72.

[5] Zhao Hai. Retrospect and Prospect of the New Rural Cooperative Medical System in China [J], Rural Finance Research, 2013(4): 11-16.

[6] Li Liqing. The Research on the Sustainable Development of the New Rural Cooperative Medical System [J], Chinese Health Service Management,2012(1): 36-40.

[7] Wang Yiqiu, Zhang Bing, Liu Xiaoling. The Research on the Demand Characteristic and Influence Factors of Rural Medical Service--- Based on the Analysis of China Health and Nutrition Survey (CHNS) [J], Industrial Economics Research, 2009(5): 74-80.

[8] Liu Guoen, Cai Chunguang, Li Lin. Empirical Analysis on Elderly Medical Security and Medical Demand in China[J], Economic Research , 2011(3): 95-107.

[9] Sun Jian. Study on the Demand for Medical Care in Rural China [J], Journal of Agrotechnical Economics ,2009(3).

[10] Cheng Lingguo, Zhang Ye.New Rural Cooperatives: Economic Performance or Medical Performance?[J], Economic Research , 2012(1): 120-133.

[11] Ye Minghua, Medical services to farmers: luxury or necessity ---Based on a comparative study of urban and rural medical demand income elasticity from 1990-2009 [J], Agricultural Economic Research , 2011(6): 30-34.

[12] Yang Hongyan. Public Nature, Efficiency and Profitability - the New Rural Cooperative Medical Management and Innovation[J], Journal of Wuhan University (Philosophy and Social Sciences ),2010(1): 96-102.

[13] Kong Xiangli, Lei Jun. Supplies of Rural Quasi Public Goods by Non-Profitable Organizations[J], Rural Economy,2011(2): 6-10.

[14] He Xiaobo, Zhang Tiantian. Nonprofit Organization Participates in the Rural Public 
Goods Supply [J], Xi 'an Academy of Ssocial Sciences 2012(2): 31-32.

[15] He Anhua, Tu Shengwei. An Analysis Framework of Diversified Suppliers and Their Boundaries of Rural Public Goods Supply[J], Agricultural Economics and Management , 2013 (1): 88-96.

[16] Dong Mingtao, Sun Yu. Research on Cooperation Mode of China's Rural Public Products Supply [J], Inquiry into Economic Issues ,2010(10): 33-38.

[17] Zhou Yanfeng, Luo Wenen, Huang Guang. Non-profit Organization Multiple Constituencies-orientation: A Study on Antecedents and Performance Consequence-Empirical Study of Blood Transfusion Services in Six Provinces in China[J], Management World, 2008(8): 59-68.

[18] Hu Yangcheng, Cai Ning. Analysis on Nonprofit Organization Market-oriented Incentive from the Perspective of Resource Dependence [J], Social Scientist, 2008(3): 120-12.

[19] Hou Jundong, Du Lanying, Li Jianfeng. Overseas Marketing Academic Research on Non-profit Organization Marketing and Enlightenment [J], East China Economic Management , 2009(2): 132-137. 